\title{
Polymorphism of Alternative Splicing of Major Histocompatibility Complex Transcripts in Wild Tiger Salamanders
}

\author{
Zafer Bulut • Cory R. McCormick • \\ David H. Bos · J. Andrew DeWoody
}

Published online: 21 May 2009

(C) Springer Science+Business Media, LLC 2009

Erratum to: J Mol Evol (2008) 67:98-75

DOI 10.1007/s00239-008-9125-1

In the published version of this article, Table 1 presented mislabeled allele names. A corrected Table 1 is shown here.

Zafer Bulut, Cory R. McCormick, and J. Andrew DeWoody contributed equally to this work.

The online version of the original article can be found under doi:10.1007/s00239-008-9125-1.

Z. Bulut · C. R. McCormick · D. H. Bos · J. A. DeWoody

The Bindley Bioscience Center and Department of Forestry \& Natural Resources, Purdue University, West Lafayette,

IN 47907-1159, USA

J. A. DeWoody $(\bowtie)$

Department of Forestry \& Natural Resources, Purdue University,

West Lafayette, IN 47907-1159, USA

e-mail: dewoody@purdue.edu 
Table 1 Relative transcript ratios at the Amti-DAB gene (showing three RT-PCR replicates from both gill and spleen) and genotype based on DNA sequencing

\begin{tabular}{|c|c|c|c|c|c|c|c|}
\hline \multirow[t]{2}{*}{ Sample No. } & \multicolumn{3}{|l|}{ Gill } & \multicolumn{3}{|c|}{ Spleen } & \multirow{2}{*}{$\begin{array}{l}\text { Amti-DAB } \\
\text { genotype }\end{array}$} \\
\hline & $\mathrm{R} 1$ & $\mathrm{R} 2$ & $\mathrm{R} 3$ & R1 & $\mathrm{R} 2$ & R3 & \\
\hline 6574 & 0.21 & 0.22 & 0.29 & 0.16 & 0.19 & 0.25 & 09/09 \\
\hline 6575 & 0.23 & 0.23 & 0.24 & 0.15 & 0.15 & 0.17 & $04 / 09$ \\
\hline 6576 & 0.16 & 0.19 & 0.19 & 0.15 & 0.16 & - & $04 / 07$ \\
\hline 6577 & 0.09 & 0.12 & 0.15 & 0.06 & 0.10 & 0.13 & 07/07 \\
\hline 6578 & 0.21 & 0.21 & 0.22 & 0.14 & 0.15 & 0.15 & 04/09 \\
\hline 6579 & 0.36 & 0.47 & 0.57 & 0.19 & 0.21 & 0.27 & $01 / 06$ \\
\hline 6580 & 0.12 & 0.13 & 0.16 & 0.10 & 0.11 & 0.12 & 06/09 \\
\hline 6581 & 0.11 & 0.32 & 0.35 & 0.13 & 0.14 & 0.16 & 07/09 \\
\hline 6582 & 0.14 & 0.16 & 0.17 & 0.17 & 0.17 & 0.21 & 07/09 \\
\hline 6583 & 0.29 & 0.32 & 0.33 & 0.19 & 0.21 & 0.22 & $01 / 02$ \\
\hline 6584 & 0.68 & 0.70 & 0.73 & 0.10 & 0.11 & 0.11 & $01 / 07$ \\
\hline 6585 & 0.42 & 0.44 & 0.49 & 0.06 & 0.11 & 0.14 & $01 / 07$ \\
\hline 6586 & 0.28 & 0.29 & 0.30 & 0.18 & 0.18 & 0.18 & $02 / 04$ \\
\hline 6587 & 0.15 & 0.16 & 0.16 & 0.57 & 0.61 & 0.74 & $07 / 07$ \\
\hline 6588 & 0.20 & 0.20 & 0.21 & 0.15 & 0.15 & 0.17 & $01 / 09$ \\
\hline 6589 & 0.18 & 0.20 & 0.20 & 0.14 & 0.15 & 0.15 & 09/09 \\
\hline 6590 & 0.20 & 0.20 & 0.21 & 0.16 & 0.16 & - & 01/09 \\
\hline 6591 & 0.10 & 0.17 & 0.17 & 0.10 & 0.10 & 0.11 & 01/01 \\
\hline 6592 & 0.26 & 0.29 & 0.29 & 0.13 & 0.13 & 0.14 & $04 / 09$ \\
\hline 6593 & 0.36 & 0.37 & 0.39 & 0.12 & 0.12 & 0.13 & $01 / 07$ \\
\hline 6594 & 0.25 & 0.25 & 0.26 & 0.20 & 0.23 & 0.26 & $03 / 06$ \\
\hline 6595 & 0.48 & 0.48 & 0.74 & 0.10 & 0.11 & 0.13 & $01 / 01$ \\
\hline 6596 & 0.21 & 0.21 & 0.24 & 0.19 & 0.23 & 0.25 & $04 / 06$ \\
\hline 6597 & 0.15 & 0.15 & 0.18 & 0.11 & 0.11 & 0.12 & $01 / 04$ \\
\hline 6598 & 0.31 & 0.34 & 0.35 & 0.11 & 0.12 & 0.12 & $01 / 01$ \\
\hline 6599 & 0.17 & 0.17 & 0.17 & 0.10 & 0.11 & 0.15 & $01 / 07$ \\
\hline 6600 & 0.22 & 0.22 & 0.26 & 0.10 & 0.11 & 0.13 & 07/09 \\
\hline 6601 & 0.41 & 0.41 & 0.44 & 0.08 & 0.11 & 0.12 & 01/01 \\
\hline 6602 & 0.27 & 0.28 & 0.28 & 0.12 & 0.14 & 0.16 & 07/09 \\
\hline 6603 & 0.23 & 0.31 & 0.32 & 0.10 & 0.10 & 0.11 & $01 / 07$ \\
\hline 6604 & 0.14 & 0.17 & 0.18 & 0.12 & 0.13 & 0.16 & 07/09 \\
\hline 6605 & 0.12 & 0.15 & 0.16 & 0.11 & 0.11 & 0.13 & $01 / 01$ \\
\hline 6606 & 0.23 & 0.24 & 0.25 & 0.13 & 0.14 & 0.14 & 09/09 \\
\hline 6607 & 0.19 & 0.19 & 0.23 & 0.09 & 0.11 & 0.11 & $04 / 04$ \\
\hline Grand Mean & 0.26 & & & 0.15 & & & $\mathrm{n} / \mathrm{a}$ \\
\hline
\end{tabular}

